\title{
Contabilidade ambiental: análise da participação no índice de sustentabilidade empresarial (ise) e a rentabilidade das empresas listadas na $[\mathrm{B}]^{3}$
}

Vanessa de Menêses Silva

Mestranda em Ciências Contábeis - Programa de Pós-Graduação em Ciências Contábeis da Universidade Federal da Paraíba.

vanessa_m.s@outlook.com

Wenner Glaucio Lopes Lucena

Doutor em Ciências Contábeis pela UnB

Professor do Programa de Pós-Graduação em Ciências Contábeis da Universidade Federal da Paraíba wdlucena@yahoo.com.br

\section{Editor Científico: José Edson Lara}

Organização Comitê Científico

Double Blind Review pelo SER/OJS

Recebido em 28.12.2018

Aprovado em 25.03.2019 


\title{
Resumo
}

Investimentos ambientalmente sustentáveis são fatores importantes para que as empresas sejam competitivas e eles podem refletir em um melhor desempenho econômico-financeiro empresarial. O objetivo deste artigo foi de analisar a relação entre a participação das empresas no Índice de Sustentabilidade Empresarial (ISE) e a sua rentabilidade. Para tanto, teve como amostra de pesquisa o total de 590 empresas listadas na Bolsa Brasil Balcão, e o período analisado englobou os anos de 2010 a 2016. As relações entre as variáveis foram estudadas por meio da regressão do modelo de dados em painel com efeitos fixos e erros padrão robustos. Os resultados obtidos na pesquisa revelaram a ocorrência de uma relação positiva entre a participação das empresas no Índice de Sustentabilidade Empresarial e o seu ROA (Retorno sobre o Ativo), assim, entende-se que isto pode ser um atrativo para que as empresas se empenhem em participar do índice a fim de melhorar seu desempenho.

Palavras-chave: Investimentos ambientalmente sustentáveis; Índice de Sustentabilidade Empresarial (ISE); ROA (Retorno sobre o Ativo).

\section{Environmental accounting: analysis of the participation in the business sustainability index (ise) and the profitability of the companies listed in $[\mathrm{B}]^{3}$}

\begin{abstract}
Environmentally sustainable investments are important factors for companies to be competitive and they can reflect in a better economic-financial business performance. The objective of this article was to analyze the relationship between the participation of companies in the Corporate Sustainability Index (ISE) and their profitability. In order to do so, 590 companies listed on the Stock Exchange of Brazil were surveyed, and the period analyzed covered the years 2010 to 2016. The relationships among the variables were studied through regression of the panel data model with effects fixed and robust standard errors. The results obtained in the research revealed a positive relationship between the participation of companies in the Corporate Sustainability Index and their ROA (Return on Asset), so it is understood that this can be an attractive for companies to strive participate in the index in order to improve its performance.
\end{abstract}

Keywords: Environmentally sustainable investments; Corporate Sustainability Index (ISE); ROA (Return on Asset).

\section{Contabilidad ambiental: análisis de la participación en el índice de sostenibilidad empresarial (ise) y la rentabilidad de las empresas listadas en la $[\mathrm{B}]^{3}$}

\section{Resumen}

Las inversiones ambientalmente sostenibles son factores importantes para que las empresas sean competitivas y que puedan reflejar en un mejor desempeño económico-financiero empresarial. El objetivo de este artículo fue analizar la relación entre la participación de las empresas en el Índice de Sustentabilidad Empresarial (ISE) y su rentabilidad. Para ello, tuvo como muestra de investigación el total de 590 empresas listadas en la Bolsa Brasil Balcão, y el 
período analizado englobó los años de 2010 a 2016. Las relaciones entre las variables fueron estudiadas por medio de la regresión del modelo de datos en panel con efectos fijos y errores estándar robustos. Los resultados obtenidos en la investigación revelaron la ocurrencia de una relación positiva entre la participación de las empresas en el Índice de Sustentabilidad Empresarial y su ROA (Retorno sobre el Activo), así, se entiende que esto puede ser un atractivo para que las empresas se comprometen en participar del índice para mejorar su funcionamiento. Palabras clave: Inversiones ambientalmente sostenibles; Índice de Sustentabilidad Empresarial (ISE); ROA (Retorno sobre el activo).

\section{Introdução}

De acordo com Barakat (2013), no início do século XX, devido à pouca concorrência existente na época, a gestão das empresas estava voltada, principalmente, para a produção. A partir da queda de barreiras comerciais e a integração dos mercados, afirma ainda a autora, a competição entre as empresas se acirrou, sendo preciso mudar as estratégias de negócio e incorporar questões como qualidade, marca, inovação e outros atributos que pudessem diferenciar as empresas e seus produtos. As questões relativas à responsabilidade social das organizações até então não eram discutidas.

Com a conscientização da sociedade acerca das questões sociais e ambientais, as empresas se viram cobradas e obrigadas a adotarem atitudes socialmente e ambientalmente sustentáveis. Corrobora com o exposto, Mazzer (2015), ao afirmar que os consumidores passaram a exigir das empresas a adoção de condutas mais éticas, transparentes e socialmente responsáveis e, consequentemente, as mesmas passaram a se preocupar, de forma cada vez mais crescente, com a responsabilidade das suas atividades. Gandhi, Selladurai e Santhi (2006) complementam ao alegarem que a legislação, os consumidores e a comunidade configuram cada vez mais uma força para o engajamento das empresas aos benefícios ambientais e sociais.

De acordo com o site da [B] ${ }^{3}$ - Bolsa Brasil Balcão (2016), a partir da década de 1990, iniciou-se uma tendência dos investidores procurarem empresas socialmente responsáveis, sustentáveis e rentáveis para aplicarem seus recursos, sendo essas aplicações denominadas de investimentos socialmente responsáveis (ISR), que consideram que empresas sustentáveis geram valor ao acionista no longo prazo, tendo em vista estarem preparadas para enfrentar os riscos econômicos, sociais e ambientais.

Para Serpa e Fourneau (2007), atuar como uma companhia que busca trazer melhorias para a sociedade, passou a ser considerado como importante meio de adquirir vantagem competitiva. Os investimentos realizados em atividades de RSC (Responsabilidade Social 
Corporativa) ou em organizações que desempenham atividades desse caráter, são chamados Investimentos Socialmente Responsáveis (ISR). Segundo Revelli e Viviani (2014), ISR são investimentos que incorporam valores éticos, proteção do ambiente, melhoria nas condições sociais e boa governança corporativa.

O ISE (Índice de Sustentabilidade Empresarial), criado em 2005, de acordo com informações do site da $[\mathrm{B}]^{3}(2016)$, tem como principal propósito, refletir o retorno de uma carteira composta por ações de empresas reconhecidamente comprometida com a responsabilidade social e a sustentabilidade empresarial, e, também, que atuem como promotoras de boas práticas no meio empresarial brasileiro. Considerado como um benchmark, ou seja, marca de referência, o ISE é baseado em eficiência econômica, equilíbrio ambiental, justiça social e governança corporativa.

As empresas que divulgam informações por meio do questionário ISE, se diferenciam das demais por apresentarem qualidade de informação ambiental, compromisso com o desenvolvimento sustentável, equidade, transparência e prestação de contas, natureza do produto, além do desempenho empresarial nas dimensões econômico-financeira, social, ambiental e de mudanças dinâmicas $\left([\mathrm{B}]^{3}, 2016\right)$. De maneira geral, tal índice cria mecanismos em prol do desenvolvimento da sociedade, a partir do estímulo da responsabilidade ética das organizações.

Desta forma, as empresas se veem compelidas a desenvolverem suas atividades de forma sustentável, pois à medida que o espaço no mercado fica mais limitado, as perspectivas de lucro e crescimento ficam cada vez menores, pois como Roman et al. (2012) expõem, a capacidade de competição de uma organização depende da sua capacidade de mudar e de desenvolver novas direções estratégicas, no qual o processo de pensar o novo, de considerar ideias e soluções que ainda não são conhecidas, assume um importante papel em termos de aquisição de vantagem competitiva.

Considerando que uma das maneiras de descobrir o quanto do total do capital investido na empresa retorna, é realizando o cálculo do retorno sobre o Ativo Total (ROA). Essa ferramenta pode ser utilizada para analisar a relação do que foi investido e o retorno para a empresa, pois o ROA apresenta percentualmente a relação entre o lucro e os bens e direitos pertencentes à entidade.

Lankoski (2008) relata que, a teoria dos stakeholders trata da existência de uma relação entre as práticas de RSC e o desempenho financeiro, e que as práticas de sustentabilidade levam ao aumento do valor dos bens intangíveis da empresa. Considera-se também que o ISE propicia 
aos investidores a possibilidade de identificar, no mercado financeiro brasileiro, as melhores empresas no que se refere à sustentabilidade. Dessa forma, espera-se que os investimentos em práticas de RSC gerem uma valorização nos preços das ações das empresas integrantes desse índice. Essa valorização pode ser considerada como uma "recompensa pela sustentabilidade".

Diante disso, tendo em vista que os investimentos no meio ambiente são considerados fatores importantes para que as empresas sejam competitivas e que tais gastos podem refletir em um melhor desempenho econômico-financeiro empresarial, o problema de pesquisa assim se apresenta: Qual é a relação entre a participação das empresas no Índice de Sustentabilidade Empresarial (ISE) e a sua rentabilidade? E têm-se como objetivo geral analisar a relação entre a participação das empresas no Índice de Sustentabilidade Empresarial (ISE) e a sua rentabilidade.

Sendo assim, este estudo se justifica pela relevância de informar o impacto que os investimentos socioambientais provocam na rentabilidade das empresas que compõem o índice de sustentabilidade empresarial. Embora pesquisas sobre o índice de sustentabilidade já tenham sido desenvolvidas nos últimos anos, não foram observados estudos que relacionassem a participação das empresas no ISE com a sua rentabilidade. Além disso, é de grande importância estudar as empresas que compõem tal índice, pois percebe-se que no decorrer dos anos ocorreu um aumento no número de empresas que adotaram práticas sustentáveis na gestão das suas atividades.

Destarte, as informações levantadas nesta pesquisa podem fomentar o desenvolvimento de novas pesquisas, além de servirem como parâmetro para as empresas que adotam práticas de investimentos ambientais e que pertencem ao ISE, a fim de que as mesmas analisem o reflexo desses gastos na sua rentabilidade e, assim, possam tomar decisões apropriadas relacionadas à gestão ambiental, no sentido de agredir cada vez menos o meio ambiente sem que sua rentabilidade seja comprometida, bem como incentivar e despertar o interesse de outros pesquisadores para o desenvolvimento de novas pesquisas sobre esta temática.

\section{Fundamentação Teórica}

A teoria sobre Responsabilidade Social surgiu na década de 1950, onde Bowen (1957), um de seus precursores, afirmava que os negócios são centros vitais de poder e decisão e as ações das empresas afetam a vida de todos os cidadãos em muitos aspectos. Questionando quais seriam as responsabilidades que a sociedade espera dos "homens de negócios", ele sustentou a 
ideia de que as empresas devem compreender melhor o seu impacto social, e que o desempenho social e ético deve ser avaliado por intermédio de auditorias incorporadas à gestão.

Dessa forma, as empresas socialmente responsáveis criam efeitos positivos de longo prazo, como o aumento do valor da empresa, a construção de uma boa imagem, o fortalecimento da relação entre stakeholders, a redução de alguns tipos de riscos, a licença para operar e isso pode gerar um impacto positivo nas vendas.

Conforme Silveira, Yoshinaga e Borba (2005), a teoria dos stakeholders possui seus vínculos principalmente na sociologia, no comportamento organizacional e na política de interesses de grupos específicos. Freeman e McVea (2000) conceituam essa teoria como a formulação e a implementação, pelos administradores, de processos que satisfaçam os grupos interessados na empresa. A principal função desses processos seria gerenciar e integrar os relacionamentos e os interesses dos acionistas, funcionários, clientes, fornecedores, comunidades, entre outros grupos, de forma a assegurar o sucesso da empresa em longo prazo.

Outrossim, de acordo com informações do site da $[\mathrm{B}]^{3}$ (2016), na atual década iniciouse uma tendência mundial dos investidores procurarem por empresas socialmente responsáveis, sustentáveis e rentáveis para aplicar seus recursos, sendo estas aplicações denominadas de “investimentos socialmente responsáveis" (SRI).

Para Vellani e Ribeiro (2009), desenvolver-se sustentavelmente implica em promover o desenvolvimento econômico concomitantemente à preservação ambiental, de modo a satisfazer as necessidades atuais sem comprometer a capacidade das próximas gerações satisfazerem suas futuras necessidades. Em relação a isso, é importante ressaltar também que, segundo o Instituto Ethos (2013), responsabilidade social empresarial refere-se a forma de gestão que é definida por uma relação ética e transparente da empresa com todos os seus públicos e pelo estabelecimento de metas empresariais que promovam o desenvolvimento sustentável da sociedade.

De acordo com Rover, Borba e Murcia (2009), a partir das transformações ocorridas no ambiente em que as empresas atuam, percebeu-se um aumento da demanda por maior disclosure, accountability, práticas de governança corporativa e conduta ética por parte das companhias, especialmente no que diz respeito a informações de caráter ambiental. Outrossim, os autores relatam que a adaptação das empresas às práticas ambientais exigidas por seus stakeholders, promove reflexos na gestão e na forma como elas divulgam as informações sobre suas interações com o meio ambiente.

Diante disso, houve a criação de diversos investimentos socialmente responsáveis no 
Brasil, a exemplo do Unibanco, que lançou, em 2001, o primeiro serviço de pesquisa para fundos verdes, conforme mencionam Monzoni, Biderman e Brito (2006). A [B] $]^{3}$, juntamente com outras entidades (ABRAPP, ANBID, APIME, IBGC, IFC, PNUMA e Ministério do Meio Ambiente), também criou o Índice de Responsabilidade Empresarial (ISE).

A criação do ISE teve o propósito de analisar o desempenho sustentável das empresas listadas na Bolsa de valores brasileira, como também para ser utilizado como um instrumento de diferenciação em termos de qualidade e comprometimento com a sustentabilidade, baseada em eficiência econômica, equilíbrio ambiental, justiça social e governança corporativa. Desenvolvido sob o conceito de Triple Bottom Line (TBL), tripé da sustentabilidade que une as dimensões econômica, social e ambiental, e considerado uma iniciativa pioneira na América Latina, conforme menciona Kruel (2011), o ISE é considerado um referencial (Benchmark) para que possa orientar investidores a investirem em empresas sustentáveis.

O ISE também tem sido utilizado como um instrumento de comparação objetiva em relação ao desempenho das empresas de capital aberto, que se destacam por buscarem alinhar os seus preceitos aos da sustentabilidade e por adotarem práticas que contribuem para o desenvolvimento sustentável ([B] $\left.]^{3}, 2016\right)$. De maneira geral, tal índice foi desenvolvido com o intuito de medir o grau de sustentabilidade das empresas, mostrando, dessa forma, aos investidores e demais interessados na organização, o grau de comprometimento da organização com o meio ambiente e sociedade.

De acordo com Maehara (2013), o ISE procurou agregar valores como desenvolvimento sustentável, responsabilidade social e segurança para os acionistas, tendo, para isso, o apoio do Centro de Estudos em Sustentabilidade da Fundação Getúlio Vargas (GVces), que montou o questionário de avaliação, onde, a partir dele, são selecionadas as empresas que devem compor a carteira do ISE.

Várias pesquisas sobre RSC buscaram relacionar o desempenho social com o desempenho financeiro, a fim de demonstrar os benefícios trazidos para as empresas que se engajarem neste tipo de atividade. No entanto, os resultados encontrados nos estudos ainda são imprecisos (McWilliams \& Siegel, 2001). Alguns trabalhos constataram a existência de uma relação positiva entre o desempenho social e o desempenho financeiro, e outros encontraram relação negativa, e, ainda, alguns estudos verificaram a inexistência de relação entre eles (McWilliams et al., 2006; CRANE et al., 2008). A imprecisão desses resultados pode estar relacionada à inconsistência na definição das variáveis que representam as práticas de RSC e 
nas formas usadas para mensurar o desempenho empresarial (McWilliams et al. 2006; Madariaga \& Cremades, 2010).

A teoria dos stakeholders fundamenta a existência de uma relação neutra ou positiva entre responsabilidade social e desempenho financeiro. Nessa perspectiva, Parente e Gelman (2006) afirmam que as organizações começam a se preocupar progressivamente com a legitimidade social de suas ações ao descobrir que o posicionamento socialmente responsável pode acarretar em uma vantagem competitiva. No entanto, os estudos realizados por Rezende, Nunes e Portela (2008) e Machado, Machado e Corrar (2009) apontaram que não há diferenciação entre os retornos das empresas que compõem o ISE e os retornos das demais companhias que negociam suas ações na $[\mathrm{B}]^{3}$.

Nesse sentido, desenvolveu-se a hipótese testada neste estudo, baseada nas indicações da teoria dos stakeholders e na teoria da Responsabilidade Social (Bowen, 1957), por meio da qual buscou-se verificar a evidência empírica do efeito positivo da participação das empresas no Índice de Sustentabilidade Empresarial (ISE) na sua rentabilidade. Assim, têm-se como hipótese de pesquisa:

\section{H1: A relação entre a participação das empresas no ISE e o seu ROA é positiva nas companhias listadas na $[\mathrm{B}]^{3}$.}

\section{Metodologia}

Quanto aos seus objetivos, a presente pesquisa, segundo Andrade (2002), caracteriza-se como descritiva, pois, buscou-se identificar e analisar qual é a relação entre a participação das empresas no Índice de Sustentabilidade Empresarial (ISE) e a sua rentabilidade, afim de refutar ou reforçar o que está expresso na literatura.

No que diz respeito aos procedimentos utilizados, conforme Beuren (2013), enquadra-se como uma pesquisa bibliográfica e documental. É bibliográfica porque utilizou-se de informações e conhecimentos prévios acerca da temática abordada, por meio de consultas à artigos científicos, livros, dissertações, teses e sítios eletrônicos, tanto para a construção do referencial teórico, quanto para argumentar os resultados encontrados.

O trabalho também pode ser reconhecido como documental porque foram feitas consultas em Demonstrações Financeiras (DF), base de dados e sítios eletrônicos para obter as informações necessárias à análise. Em relação à abordagem do problema, a pesquisa se classifica como quantitativa, pois utilizou-se instrumentos de análise estatística, buscando entender o comportamento geral da amostra estudada (BEUREN, 2013). 
A amostra analisada na presente pesquisa foi composta por 590 (quinhentas e noventa empresas) empresas listadas na $[\mathrm{B}]^{3}$, inicialmente, foi identificado um total de 746 , das tais foram desconsideradas as que não apresentaram dados em pelo menos um dos anos analisados e as companhias que atuam na atividade financeira, pois seus procedimentos de mensuração contábil se diferenciam substancialmente das demais companhias, e isto, possivelmente, causaria problemas na aplicação do modelo utilizado.

O período analisado englobou os anos de 2010 a 2016. Inicialmente, foi levantado o número de empresas pertencentes à carteira do ISE em cada ano. Entretanto, vale destacar que, quando as empresas pertencentes ao ISE deixam de cumprir com determinados critérios estabelecidos, as mesmas são excluídas da carteira. Maehara (2013) enfatiza que as empresas que não estiverem em conformidade com os critérios na época da avaliação, são excluídas do índice. Dessa forma, a participação no ISE foi tratada como variável dummy, em que, caso a empresa não pertencesse a carteira do ISE em um determinado ano, atribuiu-se o valor igual a 0 , e o valor igual a 1 , se pertencer à carteira naquele ano.

De acordo com a $[\mathrm{B}]^{3}, 2016$, os critérios estabelecidos, para que as empresas possam compor o índice, são os seguintes:

- Estar entre as 200 ações mais negociadas na Bolsa um ano antes do processo de seleção e avaliação do ISE;

- Ser negociada no mínimo em 50\% dos pregões um ano antes do processo de avaliação;

- Estar em conformidade com as boas práticas sustentáveis de acordo com o que foi decidido pelo Conselho do ISE.

Posteriormente, os dados relativos as informações financeiras das empresas foram extraídos da base de dados da Comdinheiro. A fim de verificar a relação entre as variáveis, utilizou-se uma adaptação do modelo sugerido por Arruda, Vieira, Lima e Araújo (2016), conforme expresso na equação 1. Para a realização dos testes e das regressões aplicadas às varáveis do modelo, utilizou-se o software estatístico Stata, com a estruturação de dados em painel, pois, conforme Gujarati (2011), este tratamento promove dados mais informativos, com maior variabilidade e menor colinearidade entre as variáveis, mais graus de liberdade e maior eficiência.

$$
R O A_{i t}=\beta_{0}+\beta_{1} I S E_{i t}+\beta_{2} T A M_{i t}+\beta_{3} R O_{i t}+\varepsilon
$$

Em que: 
$R O A_{i t}$ - Retorno sobre o Ativo Total da empresa i no ano t, calculado pela razão entre o Lucro Líquido e o Patrimônio Líquido;

$I S E_{i t}$ - Participação da empresa i no Índice de Sustentabilidade do ano t, variável dummy, na qual atribuiu-se 1 para a inclusão da companhia e 0 na sua ausência;

$T A M_{i t}$ - Tamanho da empresa i no ano t, mensurada pelo logaritmo natural do seu ativo total;

$R O_{i t}$ - Resultado Operacional da empresa i no ano t.

A partir da realização do teste de Chow, percebeu-se que entre o modelo Pooled e o de Efeitos Fixos, o apropriado seria o de Efeitos Fixos e com a aplicação do teste de Hausman, concluiu-se que entre o modelo de efeitos aleatórios e o de efeitos fixos o mais adequado é o de efeitos fixos, por isso, para os dados analisados nesta pesquisa foi utilizado o modelo de dados em painel com efeitos fixos e erros padrão robustos.

\section{Apresentação e Análise dos Resultados}

\subsection{Análise Descritiva}

A tabela 1 nos releva informações relacionadas à estatística descritiva das variáveis do modelo para a amostra das empresas que compõem o ISE no intervalo de tempo analisado. Por meio da sua observação, percebe-se que os dados com as maiores dispersões, em torno de suas médias, foram os das variáveis Resultado operacional e o Retorno sobre o Ativo. Isto revela que a amostra de empresas estudada apresenta elevada dispersão, tanto nos dados do RO das companhias, quanto nos do ROA. O distanciamento da média também pode ser confirmado por meio da comparação entre os valores máximos e mínimos de tais variáveis. O mesmo raciocínio também foi percebido na tabela 2, que englobou todas as empresas.

\section{Tabela 1}

Estatística descritiva das variáveis do modelo para a amostra das empresas pertencentes ao ISE

\begin{tabular}{lccccc}
\hline \multicolumn{1}{c}{ Variáveis } & Média & Mediana & D.P. & Máximo & Mínimo \\
\hline ROA & 4,37 & 3,45 & 6,06 & 48,55 & $-14,373$ \\
ISE & 0,74 & 1 & 0,44 & 1 & 0 \\
Tamanho & 22,75 & 22,69 & 1,37 & 25,77 & 19,24 \\
Resultado Operacional & 1858699021 & 681862500 & 5569115418 & 37400224000 & -45996622000 \\
\hline
\end{tabular}

Fonte: Dados da Pesquisa (2017)

No que diz respeito a média da variável ISE $(0,74)$, conforme expresso na tabela 1 , tendo em vista que não foi identificada uma variação significativa das empresas que compunham o 
Índice, percebe-se que houve uma preocupação dessas companhias em manterem seu comprometimento com a sustentabilidade, baseada em eficiência econômica, equilíbrio ambiental, justiça social e governança corporativa, buscando a sua continuidade na composição da carteira do ISE.

\section{Tabela 2}

Estatística descritiva das variáveis do modelo para a amostra de todas as empresas

\begin{tabular}{lccccc}
\hline \multicolumn{1}{c}{ Variáveis } & Média & Mediana & D.P. & Máximo & Mínimo \\
\hline ROA & 18,40 & 9,54 & 897,72 & 53242,80 & $-6357,421$ \\
ISE & 0,05 & 0 & 0,22 & 1 & 0 \\
Tamanho & 21,38 & 21,65 & 2,10 & 27,53 & 11,44 \\
Resultado Operacional & 218964821,8 & 32201000 & 2492768126 & 37400224000 & -45996622000 \\
\hline Fonte: Dados da Pesquisa (2017) & & & &
\end{tabular}

A partir da observação da média do ISE $(0,05)$, demonstrada na tabela 2 , constata-se que quando a amostra se estende a todas as empresas, a realidade muda, pois, identificou-se que as empresas não demonstraram elevada participação no ISE. Com isso, entende-se que ainda há muito o que evoluir em relação a preocupação, por parte das companhias, com o desenvolvimento sustentável.

\subsection{Análise Inferencial}

Inicialmente, buscou-se analisar apenas a amostra das empresas participantes da carteira do ISE. Dessa forma, o objetivo era avaliar se o fato das empresas participarem ou não do ISE em algum dos anos analisados afetaria a sua rentabilidade em relação a das empresas que se mantiveram constantes, participando do índice em todos os anos. No entanto, a partir das informações expressas na tabela 3, percebe-se que os resultados demonstraram a ausência de significância estatística entre a variável de interesse "ISE" e a dependente "ROA", revelando que não foi identificada relação entre elas. Corroborando com os achados nos estudos desenvolvidos por McWilliams et al. (2006), Crane et al. (2008), Rezende, Nunes e Portela (2008) e Machado, Machado e Corrar (2009).

\section{Tabela 3}

Resultado da regressão com Efeitos Fixos e erro padrão robusto para as empresas do ISE

\begin{tabular}{lccccc}
\hline Variável & Coeficiente & Erro Padrão & Razão-t & p-valor & \\
\hline const & 43,7126 & 13,425 & 3,2561 & 0,0013 & $* * *$ \\
ISE & 0,898056 & 1,31657 & 0,6821 & 0,4957 & \\
TAM & $-1,79547$ & 0,578518 & $-3,1036$ & 0,0021 & $* * *$
\end{tabular}




\begin{tabular}{lclrr} 
RO & $4,54405 \mathrm{e}-010$ & $6,76968 \mathrm{e}-011$ & 6,7123 & $<0,0001$ \\
\hline Média var. dependente & 4,366809 & D.P. var. dependente & 6,061537 \\
Soma resíduos quadrados & 8847,099 & E.P. da regressão & 5,274568 \\
R-quadrado & $26,36 \%$ & Dentro de R-quadrado & $19,49 \%$ \\
Log da verossimilhança & $-1005,764$ & Critério de Akaike & 2031,528 \\
Critério de Schwarz & 2069,458 & Critério Hannan-Quinn & 2046,661 \\
rô & 0,544781 & Durbin-Watson & 0,896848 \\
\hline
\end{tabular}

Nota: $* * *$ significa estatisticamente significativo a $1 \%$ e ** estatisticamente significativo a $5 \%$.

Fonte: Dados da Pesquisa (2017)

Considerando que o objetivo desse trabalho foi de analisar a relação entre a participação das empresas no Índice de Sustentabilidade Empresarial (ISE) e a sua rentabilidade, procurou-se testar também, a amostra das empresas listadas na $[\mathrm{B}]^{3 .}$ A princípio, com o intuito de verificar se a regressão Ordinary Least Squares (OLS - Mínimos Quadrados Ordinários), apresentava multicolinearidade, foi aplicado o teste do Fator de Inflação da Variância (VIF). Segundo Field (2009), quando os valores do VIF estão todos abaixo de 10, isto sinaliza que o modelo não apresenta multicolinearidade entre as variáveis. A tabela 4 demonstra o resultado do VIF para as variáveis.

Tendo em vista que os valores expressos na tabela 4 não se apresentaram maiores, ou iguais a 10, entende-se que não foi verificada a existência de multicolinearidade, entre as variáveis do modelo utilizado. A ausência de multicolinearidade também foi confirmada por meio do valor de tolerância (1/VIF), pois também apresentou resultados superiores a 0,20 , e, conforme Menard (1995), problemas de multicolinearidade só são evidenciados quando os valores estão abaixo de 0,20. Com isso, entende-se que as variáveis do modelo estão livres de vieses.

Tabela 4

Testes de multicolinearidade

\begin{tabular}{ccccc}
\hline \multirow{2}{*}{ TESTE } & \multicolumn{5}{c}{ VARIÁVEIS } \\
\cline { 2 - 5 } & Tamanho & ISE & Resultado Operacional & Média do VIF \\
\hline VIF & 1,08 & 1,07 & 1,01 & $\mathbf{1 , 0 5}$ \\
$\mathbf{1} /$ VIF & 0,925 & 0,936 & 0,986 & - \\
\hline
\end{tabular}

Fonte: Dados da Pesquisa (2017)

Buscando testar a existência de heterocedasticidade no modelo utilizado, realizou-se o teste de Wald, por meio do qual foi verificado que o modelo é heterocedástico, pois foi rejeitada, a $1 \%$ de significância, a hipótese nula de ocorrência de homocedasticidade (Prob $>$ chi2 $=0,00$ ). Então, foram ajustados os erros padrão, a partir da heterocedasticidade identificada, buscandose rodar o modelo com robustez. 
Com o intuito de verificar a autocorrelação das variáveis do modelo, também foi aplicado o teste de Wooldridge, a partir do resultado encontrado percebeu-se a inexistência de autocorrelação entre as variáveis (Prob>chi2 apresentou um valor alto e superior a 10\%). Diante disso, foi aceita a hipótese nula de inexistência de autocorrelação, em detrimento da rejeição da hipótese de ocorrência de autocorrelação. Este resultado revela que os erros do modelo não demonstraram um nível de autocorrelação significativo, indicando que a hipótese de independência dos erros foi satisfeita, pois não foi identificada multicolinearidade nos resíduos, e, por isso, a hipótese de teste apesenta um elevado grau de satisfação.

\section{Tabela 5}

Resultado da regressão com Efeitos Fixos e erro padrão robusto com as empresas listadas na [B] ${ }^{3}$

\begin{tabular}{lcccccc}
\hline \multicolumn{1}{c}{ Variáveis } & Coeficiente & Erro Padrão & $\mathbf{Z}$ & $\mathbf{P}>|\mathbf{Z}|$ & [95\% Conf. & Interval] \\
\hline ISE & 27,148 & 12,441 & 2,180 & 0,029 & 2,764 & 51,532 \\
TAM & $-14,441$ & 9,986 & $-1,450$ & 0,148 & $-34,013$ & 5,132 \\
RO & $2,49 \mathrm{e}^{-09}$ & $8,45 \mathrm{e}^{-10}$ & 2,95 & 0,003 & $8,38 \mathrm{e}^{-10}$ & $4,15 \mathrm{e}^{-09}$ \\
Constante & 325,176 & 225,900 & 1,440 & 0,150 & $-117,579$ & 767,931 \\
\hline
\end{tabular}

Nota: Número de observações $=3988$

Fonte: Dados da Pesquisa (2017)

Por meio dos resultados expressos na tabela 5, percebe-se que em relação à análise de todas as empresas listadas na bolsa, no teste de significância, o p-valor da regressão, apresentou-se inferior a 5\%, para a variável explicativa e de interesse ISE, o que remete a significância desta em relação a variável dependente ROA. Ainda, a partir do sinal positivo apresentado no coeficiente da variável ISE, entende-se também que a relação desta com o ROA é positiva, demonstrando que a inclusão das empresas na carteira do ISE tende a acarretar no aumento do seu ROA.

De acordo com Lankoski (2008) uma das explicações para essa relação positiva, baseiase na teoria dos stakeholders, que trata da existência de uma relação entre as práticas de RSC e o desempenho financeiro, e que as práticas de sustentabilidade levam ao aumento do valor dos bens intangíveis da empresa, elevando o seu ativo total. Dessa forma, espera-se que os investimentos em práticas de RSC gerem uma valorização nos preços das ações das empresas integrantes desse índice. Essa valorização pode ser considerada como uma "recompensa pela sustentabilidade" o que refletiria, positivamente, no seu ROA. 


\section{Considerações Finais}

A proposta deste trabalho foi de analisar a relação entre a participação das empresas no Índice de Sustentabilidade Empresarial (ISE) e a sua rentabilidade, sob a ótica da teria sobre Responsabilidade Social, que emergiu na década de 1950, tendo o Bowen (1957) como um de seus principais precursores e da teoria dos Stakeholders que considera a existência de uma relação entre as práticas de Responsabilidade Social Corporativa e o desempenho financeiro.

De maneira geral, os resultados obtidos relevaram a ocorrência de uma relação positiva entre a participação das empresas no Índice de Sustentabilidade Empresarial e o seu ROA, levando, com isso, a não rejeição da hipótese testada, na qual afirmou-se que a relação entre a participação das empresas no ISE e o seu ROA é positiva nas companhias listadas na $[\mathrm{B}]^{3}$. Revelando concordância com o que fundamenta a teoria dos stakeholders, também explicada no estudo de Parente e Gelman (2006), no qual os autores relatam que as organizações estão buscando se preocupar mais com a legitimidade social de suas ações, pois perceberam que o posicionamento socialmente responsável pode acarretar em uma vantagem competitiva.

Por outro lado, ao analisarmos apenas a amostra de empresas que integraram a carteira do ISE, percebemos que quando elas participam do Índice em pelo menos um dos anos e posteriormente deixam de participar em algum período, isso não interfere em seu ROA, ou seja, o resultado revelou que a permanência delas na composição do Índice de todos os anos não refletiu na sua rentabilidade. Contribuindo para reafirmar os achados nos trabalhos de McWilliams et al. (2006) e Crane et al. (2008).

Diante do exposto, entende-se que é vantajoso para as companhias de capital aberto investirem seus recursos em atividades de responsabilidade social corporativa, tanto de forma direta, com práticas dentro da própria organização, quanto patrocinando instituições filantrópicas que atuam nessa área de desenvolvimento sustentável, a fim de integrarem ao ISE. Mas, percebeu-se também que sua permanência neste índice não acarretará em frequentes aumentos no seu ROA.

No desenvolvimento deste trabalho foram identificadas algumas as limitações, por isso sugere-se para futuros estudos a análise de outras bolsas de valores, com o intuito de comparar a realidade externa com a do nosso país, como também a utilização de diferentes variáveis que representem a rentabilidade das empresas sob outras ópticas. 


\section{Referências}

Andrade, M. M. (2002). Como preparar trabalhos para cursos de pós-graduação: noções práticas. 5. ed. São Paulo: Atlas.

Arruda, M. P., Vieira, C. A. M., Lima, R. J. V. S., \& Araújo, A. O. (2016). Custos Ambientais de acordo com o potencial impacto poluidor listado pela Lei $N^{\circ}$ 10.165/2000. Revista em Agronegócio e Meio Ambiente (RAMA), 2 (3), 695-717.

Barakat, S. R. (2013) Alinhamento entre Responsabilidade Social Corporativa e Estratégia: Estudo do Caso Itaú Unibanco. Dissertação de Mestrado em Ciências Contábeis, Universidade de São Paulo, São Paulo, SP, Brasil.

BEUREN, I. M. (2013). Como elaborar trabalhos monográficos em contabilidade: teoria e prática. 3 ed. São Paulo: Atlas.

$[\mathrm{B}]^{3}$ - Bolsa Brasil Balcão. Índice de Sustentabilidade Empresarial - ISE. Disponível em: <http://www.bmfbovespa.com.br/indices/Resumolndice.aspx? Indice=ISE\&idioma=pt-br $>$. Acesso em: 25 nov. 2016.

$[\mathrm{B}]^{3}$ - Bolsa Brasil Balcão; ISE. Metodologia do Índice de Sustentabilidade Empresarial (ISE). Disponível em: <http://www.bmfbovespa.com.br/Indices/download/ISE-Metodologia-ptbr.pdf>. Acesso em: 26 nov. 2016.

Bowen, H. R. (1957) Responsabilidades Sociais do Homem de Negócios. Rio de Janeiro: Civilização Brasileira.

Crane, A., Mcwilliams, A., Matten, D., Moon, J., \& Siegel, D. S. (2008) The Corporate Social Responsibility Agenda. In: The Oxford Handbook of Corporate Social Responsibility. New York: Oxford University Press.

Field, A. (2009). Descobrindo a estatística usando o SPSS. 2 ed. Porto Alegre: Artmed.

Freeman, R. E., \& Mcvea, J. (2000). A stakeholder approach to strategic management. In: M. HITT, R. E. FREEMAN, J. HARRISON, Handbook of strategic management, 189-207. Oxford: Blackwell Publishing.

Gandhi, N. M.; Selladurai, V.; Santhi, P. (2009) Unsustainable Development to Sustainable Development: A Conceptual Model. Coimbatore/India: Kumaraguru College of Technology, 2006. KRAISORNSUTHASINEE, S.; SWIERCZEK, F. Doing Well By Doing Good in Thailand. Social Responsibility Journal, 5 (4), 550-565.

Gujarati, D. (2011) Econometria Básica. 5. ed. Rio de Janeiro: Elsevier.

INSTITUTO ETHOS. Indicadores Ethos de Responsabilidade Social Empresarial. Disponível em: <http://www3.ethos.org.br/wpcontent/uploads/2013/07/IndicadoresEthos_2013_PORT.pdf>. Acesso em: 23 set. 2016.

Kruel, M. (2011) Reação do Mercado ao Ingresso (Saída) do Índice de Sustentabilidade @(Q) Revista Gestão \& Tecnologia, Pedro Leopoldo, v. 19, n. 1, p. 109-125, abr./jun. 2019 
Empresarial (ISE): Estudo de Evento e Análise de Liquidez. 2011. 125 f. Dissertação de Mestrado em Administração, Universidade Federal de Santa Maria, Santa Maria, RS, Brasil.

Lankoski, L. (2008) Corporate responsibility activities and economic performance: a theory of why and how they are connected. Business Strategy and the Environment, 17 (8), 536-547.

Machado, M. R.; Machado, M. A. V.; Corrar, L. J. (2009) Desempenho do Índice de Sustentabilidade Empresarial (ISE) da Bolsa de Valores de São Paulo. Revista Universo Contábil, 5 (2), 24-38.

Madariaga, J. G.; Cremades, F. R. (2010) Corporate social responsbility and the classical theory of the firm: are both theories irreconcilable? Innovar Journal. 20, 37.

Maehara, L. M. (2013) Análise das Empresas Excluídas da Carteira do ISE no Período de 2005 a 2012. In: Congresso USP de Controladoria e Contabilidade, São Paulo.

Mazzer, L. P. (2015) Responsabilidade Social Corporativa e Desempenho Econômico Financeiro: Um Estudo em Empresas Brasileiras. Tese de Doutorado em Ciências Contábeis, Programa Multiinstitucional e Inter-regional de Pós-Graduação em Ciências Contábeis (UnB/UFPB/UFRN), João Pessoa, PB, Brasil.

McWilliams, A., \& SIEGEL, D. S. (2001). Corporate social responsibility: a theory os the firm perspestive. Academy of Management Review, 26 (1), 117-127.

McWilliams, A., Siegel, D. S., \& Wright, P. M. (2006) Corporate Social Responsibility: Strategic Implications. Journal of Management Studies, 43 (1), 1-18.

Menard, S. Applied logistic regression analysis. Sage University Papers Series on Quantitative Applications in the Social Sciences, 2 ed., v. 106. Thousand Oaks, CA: Sage.

Monzoni, M.; Biderman, R.; Brito, R. (2006) Finanças Sustentáveis e o caso do índice de sustentabilidade empresarial da Bovespa. In: Simpósio de Administração da Produção, Logística e Operações Internacionais, 9, 2006, São Paulo.

Parente, J.; Gelman, J.J. (2006) Varejo e responsabilidade social, visão e estratégia e práticas no Brasil. 1 ed. Porto Alegre: Bookman.

Revelli, C.; Viviani, Jl. (2015). Financial performance of socially responsible investing (SRI): what have we learned? A meta-analysis. Business Ethics: A European Review, 24 (2), 158-185.

Rezende, I. A. C.; Nunes, J. G.; Portela, S. S. (2007). Um estudo sobre o desempenho financeiro do Índice Bovespa de Sustentabilidade Empresarial. Revista de Educação e Pesquisa em Contabilidade, 2 (4), 93-122.

Roman, D. J.; et al. (2012) Fatores de Competitividade Organizacional. BBR - Brazilian Business Review, Vitória/ES, 9 (1), 27-46.

Rover, S.; Borba, J. A.; Murcia, F. Dal-Ri. (2009). Características do Disclosure Ambiental em empresas brasileiras potencialmente poluidoras: Análise das Demonstrações Financeiras e dos 
Relatórios de Sustentabilidade do Período de 2005 a 2007. Contextus - Revista Contemporânea de Economia e Gestão, 7 (1), 23-36.

Serpa, D. A. F.; Fourneau, L. F. (2007). Responsabilidade social corporativa: uma investigação sobre a percepção do consumidor. Revista de Administração Contemporânea, 11 (3), 83-103.

Silveira, A. M.; Yoshinaga, C. E.; Borba, P. R. (2005) Crítica à Teoria dos Stakeholders como função-objetivo corporativa. Caderno de Pesquisas em Administração, São Paulo, 12 (1), 3342.

Vellani, C. L.; Ribeiro, M. S. (2009) Sustentabilidade e contabilidade. Revista Contemporânea de Contabilidade. UFSC, Florianópolis, ano 06, 1 (11), 187- 206. 